\title{
Modes of occurrence of tungsten in alluvial soils and river sediments in the area of the Grantcharitsa tungsten deposit, Western Rhodopes, Bulgaria
}

\section{Форми на присьствие на волфрама в алувиални почви и речни седименти в района на волфрамовото находище Грънчарица, Западни Родопи, България}

\author{
Mihail Tarassov ${ }^{1}$,Eugenia Tarassova ${ }^{1}$, Milen Stavrev $^{2}$, Aleksey Benderev $^{2}$, Elena Tacheva $^{1}$ \\ Михаил Тарасов ${ }^{1}$ Евгения Тарасова ${ }^{1}$, Милен Ставрев ${ }^{2}$, Алексей Бендерев ${ }^{2}$, Елена Тачева ${ }^{1}$ \\ ${ }^{1}$ Institute of Mineralogy and Crystallography, Bulgarian Academy of Sciences, Bulgaria, E-mail: mptarassov@gmail.com \\ ${ }^{2}$ Geological Institute, Bulgarian Academy of Sciences, Bulgaria
}

\begin{abstract}
A distinct increase in the concentration of $\mathrm{W}$ in the topsoil (from 19-20 to $71 \mathrm{ppm}$ ) is found in the vertical profile of the alluvial soil at the Grantcharitsa deposit. The distribution of $\mathrm{W}, \mathrm{Fe}$, and $\mathrm{C}$ is well correlated, which indicates a significant role of organic material and iron oxides/hydroxides formed in the soil in the chemical behavior of $\mathrm{W}$. The role in these processes of scheelite, W-containing goethite and rutile identified in the soil is insignificant.
\end{abstract}

Keywords: tungsten deposit, alluvial soils, vertical distribution of tungsten, river sediments, tungsten minerals.

\section{Introduction}

Tungsten is one of the focuses of today's environmental research, as it has recently been identified as an emerging environmental toxicant (Bolt, Mann, 2016). Soils are of particular importance in these studies - as an environment and a participant in the possible transfer of $\mathrm{W}$ in the food chain. The bioavailability of $\mathrm{W}$ depends on the soil characteristics $(\mathrm{pH}$, quantity of organic matter) and the intrinsic properties of $\mathrm{W}$ (its ions, minerals and mineral and organic bearers) and its content (Petruzzelli, Pedron, 2021). The concentration range $<0.17-5.0 \mathrm{ppm}$ and an average value of $1.7 \mathrm{ppm}$ for W in soils (Kabata-Pendias, Szteke, 2015) is an appropriate approximation to the background level of $\mathrm{W}$ in uncontaminated soils, since it is close to the abundance of $\mathrm{W}$ in the Earth's crust - $1.25 \mathrm{ppm}$. Tungsten with a higher concentration in soils is either of geogenetic origin or enters the soil as a result of industrial activity (Petruzzelli, Pedron, 2021). In the present work, we study the concentrations and modes of occurrence of $\mathrm{W}$, as well as the factors that control its distribution in soils in the area of the Grantcharitsa tungsten deposit (Western Rhodope, Bulgaria) (Tarassov et al., 2019, 2020) on the example of two vertical soil profiles in the floodplain of the Grancharitsa River. For comparison, the nearby sediments in the
Grantcharitsa River are also studied. Currently, neither mining nor geological surveys are carried out on the deposit, and the locals use the meadows here as pastures and hayfields. It is assumed that the behavior of $\mathrm{W}$ in the studied soils is mainly determined by natural processes.

\section{Material and methods}

Material. We selected two soil sampling sites on the floodplain of the Grantcharitsa River: site A is in the central part of the deposit just above the oxidation zone, and site B is located $3 \mathrm{~km}$ west, upstream of the Grantcharitsa River, in the western periphery of the deposit where oxidation processes are weak. The soils are classified as alluvial and alluvial meadow soils or fluvisols (Shishkov, Kolev, 2014). Soil samples (0.5$0.7 \mathrm{~kg}$ each) were taken with a Burkle soil sampler to a depth of $0.8-1.0 \mathrm{~m}$ at intervals of $0.2 \mathrm{~m}$. Along with the soils, two samples of sediments (about $1 \mathrm{~kg}$ each) were taken in the bed of the Grantcharitsa River nearby the soil sampling sites. Under laboratory conditions, both types of samples were dried and sieved to a fraction $<1 \mathrm{~mm}$. All materials were quartered and a portion of each material was finely ground and pressed into a pellet to determine chemical composition using SEM-EDS (for major components) and LA-ICP-MS 
analysis (for W). Powdered materials were also used for phase identification with XRD. From other parts, heavy fractions were extracted, incorporated into epoxy resin and then polished. For SEM-EDS examination, all samples were carbon coated.

Methods. SEM-EDS study was carried out on a ZEISS SEM EVO 25LS with an EDAX Trident system (Institute of Mineralogy and Crystallography (IMC), BAS) at acceleration voltages of 18 and $25 \mathrm{kV}$. EDS analysis with standards was made using an EDAX SDD Apollo 10 EDS detector and Genesis V. 6.2. software and hematite (for $\mathrm{Fe}$ ), diopside $(\mathrm{Ca}, \mathrm{Mg})$, albite $(\mathrm{Na}, \mathrm{Al}$, $\mathrm{Si})$, sanidine $(\mathrm{K})$, apatite $(\mathrm{P})$, anhydrite $(\mathrm{S})$, metal tungsten $(\mathrm{W})$, calcite $(\mathrm{C})$ as standards. LA-ICP-MS analysis was performed on a PerkinElmer ELAN DRC-e ICPMS with a New Wave UP193FX LA system (Geological Institute (GI), BAS) at $5 \mathrm{~Hz}$ pulse rate, laser energy of $7.4 \mathrm{~J} / \mathrm{cm}^{2}$ and spot size of $100 \mu \mathrm{m}$. Each sample was laser ablated in four selected areas. NIST 610 was applied as primary external standard for calibration of the analyzing system. SILLS software and the $\mathrm{SiO}_{2}$ content (as internal standard from EDS analysis) were used for data procession. XRD analysis was made on a PANanalytical EMPYREAN Diffractometer system (IMC-BAS).

\section{Results and discussion}

Distribution of tungsten and main components of soils in vertical profiles. The concentrations of $\mathrm{W}$ and $\mathrm{Fe}_{2} \mathrm{O}_{3}, \mathrm{CaO}, \mathrm{Al}_{2} \mathrm{O}_{3}, \mathrm{Na}_{2} \mathrm{O}, \mathrm{SiO}_{2}$, and $\mathrm{K}_{2} \mathrm{O}$ in soils $\mathrm{A}$ and $\mathrm{B}$ for 4 depth intervals (0-0.2, 0.2-0.4, 0.4-0.6, $0.6-0.8 \mathrm{~m}$ ) are shown graphically (black curves) in Fig. 1a. The carbon symbol is marked with an asterisk because its concentration is only an estimate of its concentration using EDS analysis. But this estimate is suitable for a relative comparison of all intervals and for identifying trends in carbon distribution. The blue vertical dashed lines represent the concentration of all measured components in the river sediments.

The two soil profiles studied show a drastically different distribution of $\mathrm{W}$ : Soil A shows a distinct zonal distribution with an increase of W content from 19-
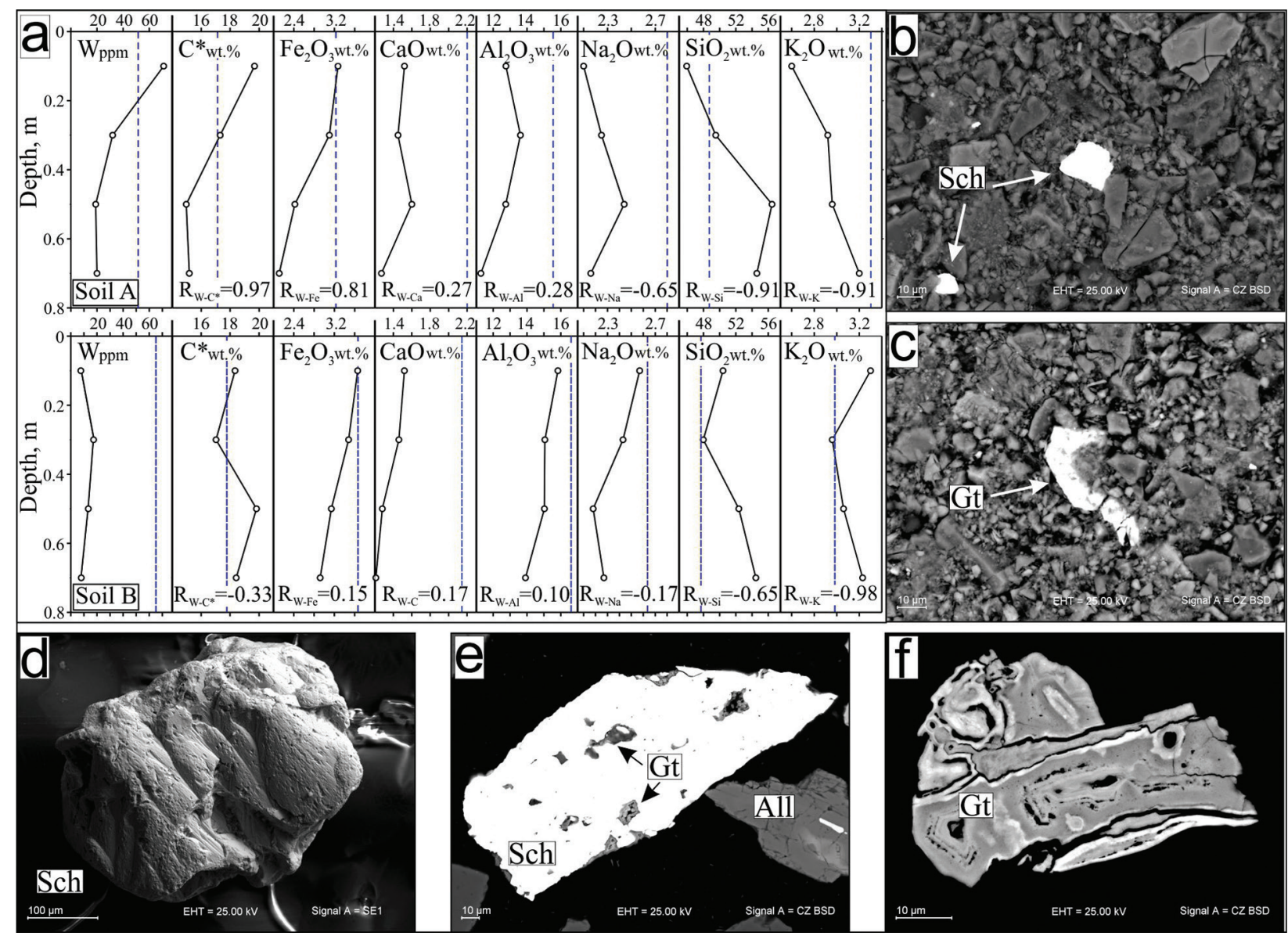

Fig. 1. $a$, distribution of $\mathrm{W}$ and $\mathrm{Fe}_{2} \mathrm{O}_{3}, \mathrm{CaO}, \mathrm{Al}_{2} \mathrm{O}_{3}, \mathrm{Na}_{2} \mathrm{O}, \mathrm{SiO}_{2}$ and $\mathrm{K}_{2} \mathrm{O}$ in vertical profiles (black curves) of samples Soils $\mathrm{A}$ and $\mathrm{B}$. The curves are arranged according to the values of the Pearson correlation coefficient (R) between $\mathrm{W}$ and other components found for Soil A; the blue vertical dotted lines indicate the concentrations of the same components in the river sediments; $b$, scheelite $(\mathrm{Sch})$ grains in pressed soil pellet (Soil A, interval 0.2-0.4 m, BSE); $c$, fragment of colloform W-containing goethite $(\mathrm{Gt})(\mathrm{WO}$ 0.6-8.4 $\mathrm{wt} \%$ ) in pressed soil pellet (Soil A, interval 0-0.2 m; BSE); $d$, rounded scheelite grain with pronounced sign of dissolution (heavy fraction, soil A, interval $0.2-0.4 \mathrm{~m}, \mathrm{SEM}) ; e$, polished scheelite $(\mathrm{Sch})$ with inclusions of goethite $(\mathrm{Gt})\left(\mathrm{WO}_{3} \sim 4 \mathrm{wt} \%\right)$ (heavy fraction, Soil A, interval 0.2-0.4 m, BSE; All, allanite); $f$, fragment of colloform goethite with variable content of $\mathrm{WO}_{3}(0.2-$ $4.0 \mathrm{wt} \%$; the lighter areas are with higher content of $\mathrm{W}$ ) (Soil A, interval 0.2-0.4 m, BSE). 
$20 \mathrm{ppm}$ to $71 \mathrm{ppm}$ in the upper interval (topsoil); while Soil B is characterized with an insignificant variation of $\mathrm{W}$ in the range 7.7-17.4 ppm. Both established concentration ranges for $\mathrm{W} 19-71$ and 7.7-17.4 ppm are higher than the metal concentration in the so-called unpolluted soils (Kabata-Pendias, Szteke, 2015). It is noteworthy (Fig. 1a) that the concentration of W in the nearby sediments are also increased - $52 \mathrm{ppm}$ (near Soil A) and $65 \mathrm{ppm}$ (near Soil B). As seen in Fig. 1a for Soil A, the distribution of $\mathrm{W}, \mathrm{C}$, and $\mathrm{Fe}$ is strongly correlated, which indicates a significant role of organic material and $\mathrm{Fe}$ compounds in the soil on the geochemical behavior of W. Similar behavior of W in soils has been reported for tungsten mining areas in China (Zheng et al, 2020). Tungsten has a distinctly negative correlation with $\mathrm{Si}$ and $\mathrm{K}$. XRD analysis of soils and sediments shows very close phase composition dominated by quartz, K-feldspar (microcline) and plagioclase. The soils are characterized by a higher content of quartz, the quantity of which increases in the deeper soil horizons. These data well correlate with the chemical composition of materials, shown in Fig. 1a.

Mineral bearers of tungsten in soils and sediments. Scheelite (Fig. 1b, d, e), W-containing goethite $\left(\mathrm{WO}_{3}\right.$ 0.2-8.4 wt.\%) (Fig. c, e, f) and sporadic W-containing rutile $\left(\mathrm{WO}_{3}\right.$ to $\left.2 \mathrm{wt} \%\right)$ are the only mineral bearers of $\mathrm{W}$ found by us in Soil A. All these minerals are alluvial and/or deluvial deposits in the studied soil and demonstrate pronounced signs of mechanical and chemical action (fragmentation - Fig. 1b, c, e, f; formation of rounded shapes and dissolution - Fig. 1d). From these minerals, the colloform goethite is formed in the oxidation zone of the deposit (Tarassov et al., 2002; Tarassov, Tarassova, 2018). It is noteworthy that the distribution of scheelite and $\mathrm{W}$-containing goethite grains does not correlate with the distribution of $\mathrm{W}$ in the studied soil. Scheelite and goethite are more common in the interval $0.2-0.4 \mathrm{~m}$ while in the topsoil $(0-0.2 \mathrm{~m})$ and in the deeper intervals $-0.6-0.8$ and $>0.8 \mathrm{~m}$ the two minerals occur sporadically. This finding confirms the above assumption about the decisive role of organic material and $\mathrm{Fe}$ compounds formed in the soil in the behavior of $\mathrm{W}$ in soil. In deeper soils intervals, the amount of accessory minerals, such as zircon, allanite, rutile (including $\mathrm{W}$-containing rutile), titanite, monazite, spessartine-almandine garnet, etc. increases significantly. Only sporadic scheelite grains were found in the second soil profile (Soil B). It was also found that the increased content of W in the studied sediments almost entirely associated with scheelite.

\section{Concluding remarks}

In the two studied soil profiles in the floodplain of the Grantcharitsa River, we found two different distributions of $\mathrm{W}$ : a distinct zonal distribution with an increase in the $\mathrm{W}$ content up to $71 \mathrm{ppm}$ in the topsoil (Soil A) and an almost uniform distribution of $\mathrm{W}$ with a slight variation within 7.7-17.4 ppm (Soil B). The increased $\mathrm{W}$ content in the topsoil is well known for tungsten mining areas in China (Zheng et al., 2020) and is attributed to the airborne transport of W-con- taining dust particles. This mechanism of increasing the $\mathrm{W}$ content could hardly be applied to the studied soils, as there are no mining activities in the Grantcharitsa deposit. The most important difference between the two studied soil sites is that the first site (Soil A) is located just above the oxidation zone of the deposit. We assume that the availability of dissolved $\mathrm{W}$ and $\mathrm{Fe}$ in the underground water draining the oxidation zone is the main reason of the increased content of $\mathrm{W}$ in Soil A. The final distribution of $\mathrm{W}$ in the soil is controlled by the organic material and the Fe oxide/ hydroxide compounds formed in the soils. The role of such minerals as scheelite and $\mathrm{W}$-containing goethite in the $\mathrm{W}$ distribution in the soil appears insignificant. Sequential extraction procedures for fractionation of W (Li et al., 2019) are required to determine the proportion of different forms of $\mathrm{W}$ in the soil.

Acknowledgements: The study was supported by the National Science Fund of Bulgaria (Contract № KP-06-OPR 03/5, 2018). The authors acknowledge the technical support from the project PERIMED BG05M2OP001-1.002-0005/29.03.2018 (2018-2023).

\section{References}

Bolt, A. M., K. K. Mann. 2016. Tungsten: an emerging toxicant, alone or in combination. - Current Environmental Health Reports, 3(4), 405-415; https://doi.org/10.1007/s40572-0160106-z.

Kabata-Pendias, A., B. Szteke. 2015. Trace elements in abiotic and biotic environments. Taylor \& Francis; https://library. oapen.org/handle/20.500.12657/41690.

Li, R., W. Wang, S. Wang, C. Lin, X. Wang, L. Meng, X. Yuan. 2019. Comparison of two sequential extraction procedures for tungsten fractionation in the tungsten mining soils. - RSC Advances, 9(61), 35456-35462; https://doi.org/10.1039/ C9RA07158J.

Petruzzelli, G., F. Pedron. 2021. The dynamics of tungsten in soil: An overview. - Environments, 8, 66; https://doi.org/10.3390/ environments 8070066 .

Shishkov, T., N. Kolev. 2014. The Soils of Bulgaria. Dordrecht Heidelberg New York London, Springer Netherlands, 208 p.; https://doi.org/10.1007/978-94-007-7784-2.

Tarassov, M. P., E. D. Tarassova. 2018. Structural and chemical evolution of mineral forms of tungsten in the oxidation zone of the Grantcharitza deposit (Western Rhodopes, Bulgaria). Bulg. Chem. Commun., 50 (Special Issue J.), 270-280.

Tarassov, M., B. Mihailova, E. Tarassova, L. Konstantinov. 2002. Chemical composition and vibrational spectra of tungsten-bearing goethite and hematite from Western Rhodopes, Bulgaria. - Europ. J. Miner., 14(5), 977-986; https://doi. org/10.1127/0935-1221/2002/0014-0977.

Tarassov, M., A. Benderev, M. Trayanova, E. Tarassova. 2019. Preliminary data on the content of $\mathrm{W}$, As and $\mathrm{U}$ in the waters in the area of the Grantcharitza deposit, Western Rhodopes. Rev. Bulg. Geol. Soc., 80, 3, 239-241.

Tarassov, M., M. Stavrev, E. Tarassova, E. Tacheva, A. Benderev. 2020. Formation and chemical composition of iron oxide precipitates from drainage waters in the western part of the Grantcharitsa deposit, Western Rhodopes. - Rev. Bulg. Geol. Soc., 81, 3, 52-54; https://doi.org/10.52215/rev. bgs.2020.81.3.52.

Zheng, X. J., M. Chen, J. F. Wang, F. G. Li, Y. Liu, Y. C. Liu. 2020. Ecological risk assessment of heavy metals in the vicinity of tungsten mining areas, Southern Jiangxi province. Soil and Sediment Contamination: An International J., 29(6), 665-679; https://doi.org/10.1080/15320383.2020.1763912. 